\title{
Effectiveness of telemedicine-guided home blood pressure compared to 24 h-ambulatory blood pressure monitoring in patients with and without chronic kidney disease
}

\author{
Xavier Galloo $\odot$, Tom Robberechts $\odot$, Patricia Van Der Niepen $\odot$ \\ Department of Nephrology and Hypertension, Universitair Ziekenhuis Brussel, VUB, Brussels, Belgium
}

\begin{abstract}
Background. Only few direct comparative studies evaluated the effectiveness of telemedicine-guided home blood pressure (tele-HBPM) compared to $24 \mathrm{~h}$ ambulatory blood pressure monitoring (ABPM) in assessing blood pressure (BP) and BP control.

Material and methods. This prospective clinical trial included patients with arterial hypertension, with $(\mathrm{n}=23)$ and without $(\mathrm{n}=18)$ chronic kidney disease and normal volunteers $(\mathrm{n}=16)$. All subjects underwent with a 1-month interval twice one-week of BP monitoring with office BP (3 measurements at 2 visits), $24 \mathrm{~h}-\mathrm{ABPM}$ and tele-HBPM during 7 consecutive days.

Results. Mean (SD) BP levels were 128/77 [19/11] mm Hg and 126/75 [14/9] mm Hg for tele-HBPM, 129/78 [17/11] $\mathrm{mm} \mathrm{Hg}$ and $127 / 75$ [14/9] mm Hg for daytime-ABPM, and 133/77 [23/12] mm Hg and 130/74 [17/11] $\mathrm{mm} \mathrm{Hg}$ for office BP, all respectively at the first and the second measurement periods. Blood pressure and BP control were comparable between the two out-of-office techniques.

Conclusion. Both out-of-office techniques (tele-HBPM and 24h-ABPM) show good agreement for systolic as well as diastolic BP, and are equally effective in assessing BP and BP control, explicitly during daytime.
\end{abstract}

Key words: arterial hypertension; office blood pressure; ambulatory blood pressure; home blood pressure; blood pressure telemonitoring; chronic kidney disease

Arterial Hypertens. 2020, vol. 24, no. 2, pages: 83-92

DOI: $10.5603 /$ AH.a2020.0010

\section{Introduction}

Office blood pressure (BP) measurement is still considered as the reference method for screening, diagnosis and management of hypertension. However, office BP may be unrepresentative of the actual BP due to the white-coat and masked hypertension phenomena [1]. In patients with chronic kidney disease $(\mathrm{CKD})$, office $\mathrm{BP}$ values often seem to be inaccurate [2]. Moreover out-of-office BP monitoring is superior to office measurements in predicting organ damage [3, 4], and is therefore considered complementary to office BP measurements [1]. Ambulatory $\mathrm{BP}$ monitoring $(\mathrm{ABPM})$ is the reference for out-of-office BP since it provides additional information on night-time BP compared to home BP

Address for correspondence: Patricia Van der Niepen, MD, PhD

Department of Nephrology and Hypertension, Universitair Ziekenhuis Brussel, Laarbeeklaan 101, 1090 Brussels, Belgium, tel: (+32) 24776055 ,

fax: (+32) 247762 30; e-mail: patricia.vanderniepen@uzbrussel.be 
monitoring (HBPM). However, there are no strong data to support superiority of either out-of-office BP measurement for hard cardiovascular or renal endpoints [5]. Although some discrepancy exists in the literature, the ESH/ESC proposes the same cutoff values for HBPM as for daytime-ABPM; and advices that abnormal values on HBPM should be confirmed by ABPM [1]. According to recent papers HBPM should have a primary role in the diagnosis, treatment and follow-up of hypertensive patients [3].

However, the data obtained by conventional HBPM are often incomplete, inaccurate, illegible or unreliable if recorded by patients in handwritten logbooks [6]. To overcome these disadvantages the use of telemonitoring has been introduced. Telemonitoring consists of an automatic remote data transmission from the point of care to the doctor's office; BP values obtained by HBPM are transferred to a computer through a telephone line, a modem or the Internet [7].

Few studies directly compared HBPM and ABPM, and only two investigators used telemedicine-guided home blood pressure (tele-HBPM) [8] (Tab. 1), Some studies did not find a significant difference between HBP and day-time-ABP, while others found significant higher or lower HBP than daytime-ABP-values [9-24]. Both studies with teleHBPM showed a significant difference, but in the opposite direction $[18,21]$.

The main objective of this study was to evaluate the effectiveness of tele-HBPM and 24h-ABPM in assessing $\mathrm{BP}$ and $\mathrm{BP}$ control in patients with arterial hypertension with and without CKD and in normotensive volunteers.

\section{Material and methods}

\section{Study design}

All subjects underwent with a 1-month interval twice one-week of BP monitoring. At the first visit (visit 1 - day 1) baseline characteristics were collected (age, sex, race, weight, length, number and type of antihypertensive medication), office BP was measured and patients were asked to fill in 3 questionnaires: (1) EQ-5D-3L questionnaire on general wellbeing, (2) Hospital Anxiety and Depression Scale (HADS) questionnaire on anxiety and depression [25, 26], and (3) Morisky Medication Adherence Scale (MMAS-8). Afterwards, 24h-ABPM was started. At the second visit (visit 2 - day 2) office BP was measured and tele-HBPM was initiated for one week. When the patient returned the HBPM-device (day 9) she/he had to fill in a questionnaire on the satisfaction concerning the type of BP measurement.
One month later the same examinations were repeated on the $3^{\text {rd }}$ and $4^{\text {th }}$ visit.

The study design is shown in Figure 1.

\section{Study sample}

Untreated normotensive (NT) volunteers and treated hypertensive (HT) patients with or without CKD were recruited during the Nephrology \& Hypertension outpatient clinic of the Universitair Ziekenhuis Brussel.

To be eligible, participants had to be at least 18 years old and had to sign the appropriate written informed consent before any study-specific procedure was performed. Hypertensive patients had to be on a stable antihypertensive drug treatment.

Criteria for exclusion were: recent cardiovascular or cerebral event, severe HT $(\mathrm{BP}>180 />110 \mathrm{~mm}$ $\mathrm{Hg}$ ), atrial fibrillation, acute kidney failure, debilitating illness, pregnancy, impossibility to measure BP in a standardized way and any kind of disorder that compromises the ability of the subject to provide written informed consent and/or to comply with study procedures.

\section{Blood pressure measurement}

Blood pressure was measured according to the current ESH/ESC guidelines [1], using a validated and calibrated device. For all types of BP measurement, the same cuff size was used around the non-dominant arm or the non-fistula arm for haemodialysis patients.

Office BP was taken with an automated oscillometric BP device (Omron HEM-705CP digital BP monitor, OMRON HEALTHCARE Co., Ltd. Kyoto, Japan), trice with a 1-minute interval, in sitting position, after 5 minutes of rest. The first of 3 measurements was always excluded in the statistical analysis. Mean office BP in patients on dialysis (CKD stage 5) was calculated as the mean BP taken once before dialysis, every 30 minutes during dialysis and once after dialysis.

Ambulatory BP was recorded with oscillometric Space-Labs monitors (SpaceLabs Healthcare, Snoqualmie, Washington, USA). The devices were programmed to obtain BP readings at 15 -minute intervals from 08:00 to 22:00 and at 30-minute intervals for the remainder of the day. Afterwards, daytime and night-time ambulatory BP's were calculated as the means of the readings obtained during actual awake and sleep time.

For the self-measurement at home, the subjects used a validated upper-arm electronic automated sphygmomanometer, the Stabil-O-Graph mobil (IEM, GmBH, Stolberg, Germany) equipped for 


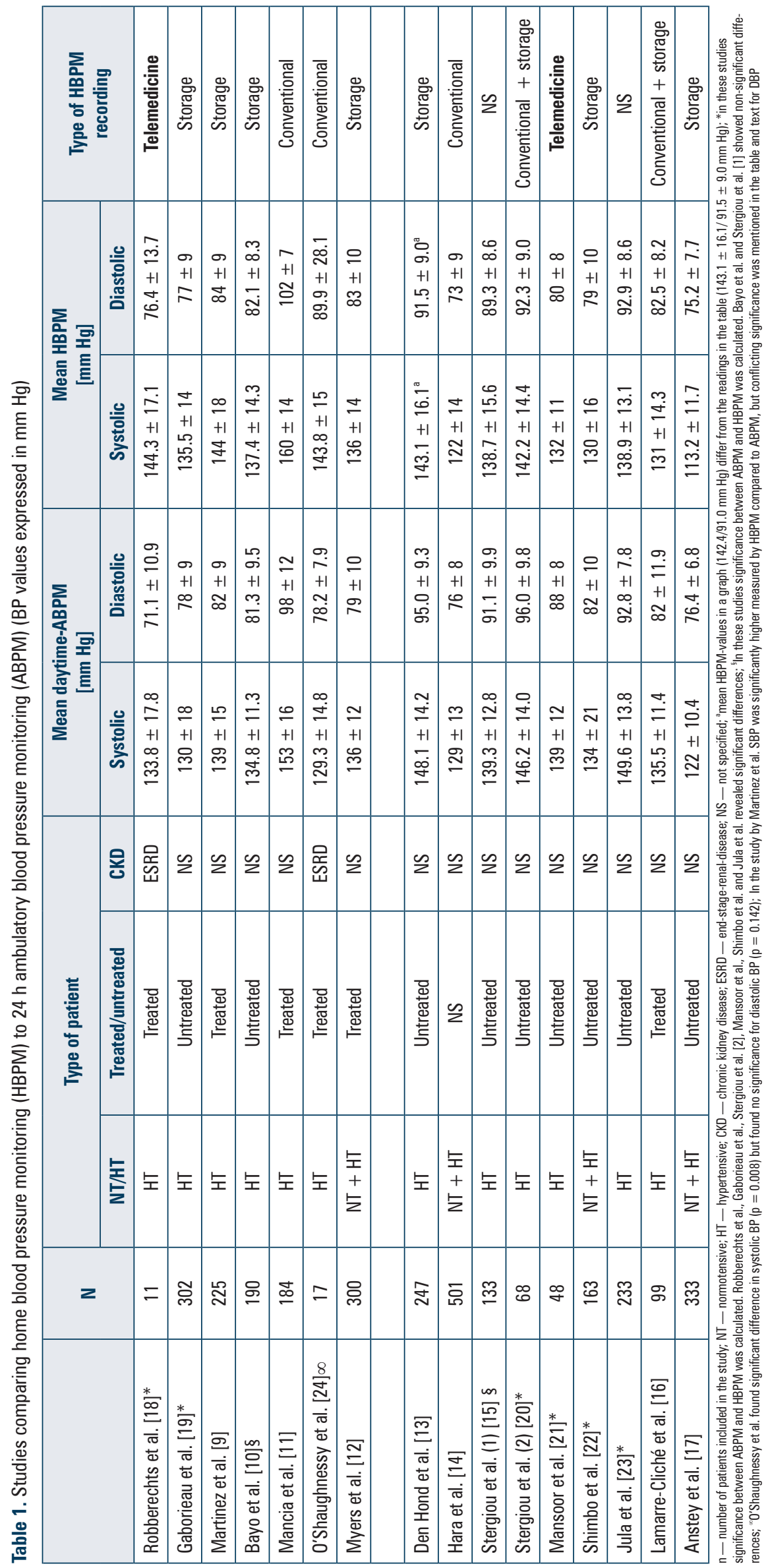




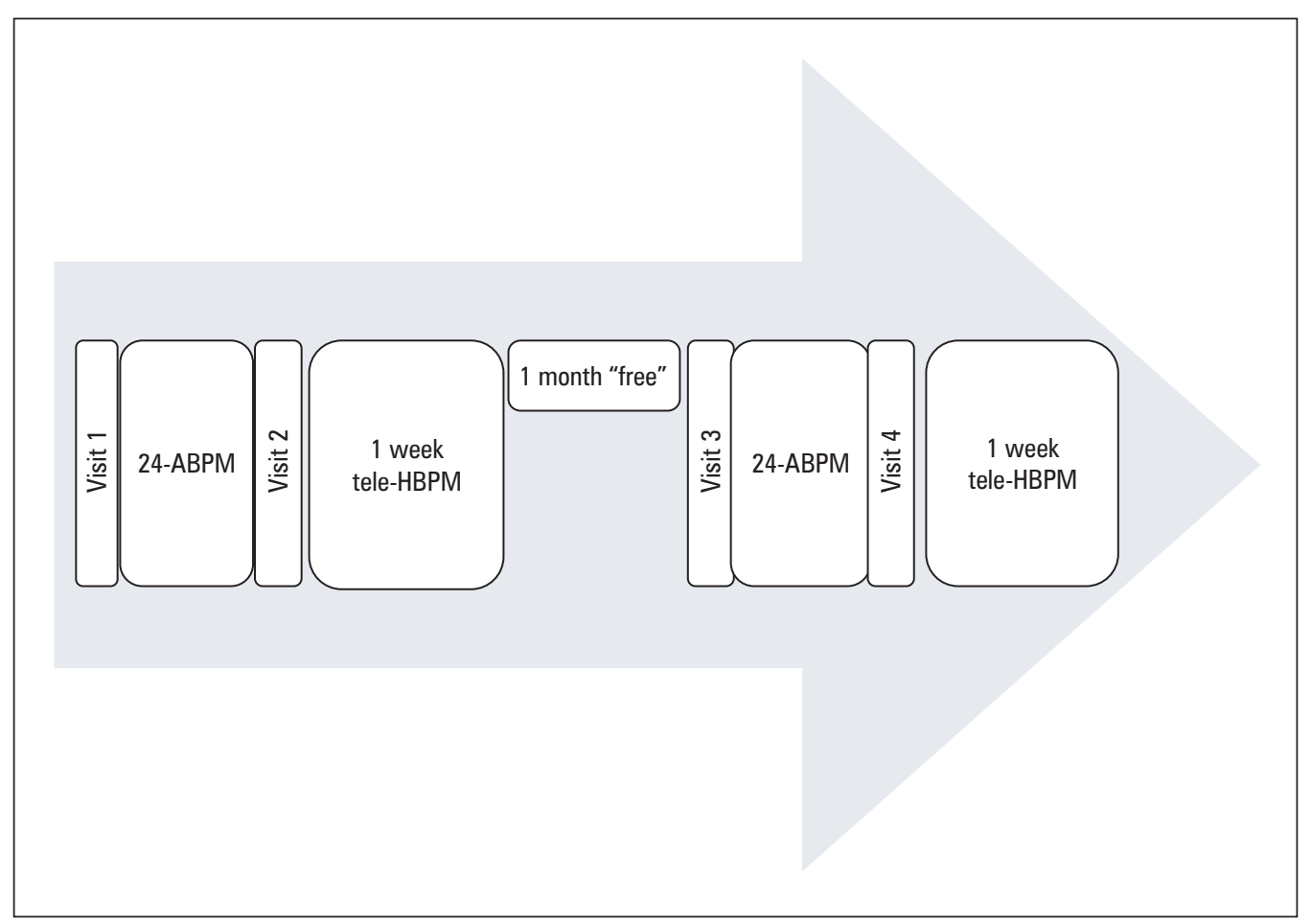

Figure 1: Study design. 24h-ABPM — $24 \mathrm{~h}$ ambulatory blood pressure monitoring; tele-HBPM — telemedicine guided home blood pressure monitoring

BP telemonitoring. Patients measured their BP trice with a 1-minute interval in the morning and in the evening (between 06:00-10:00 and 18:00-22:00, respectively) before eating and before taking any medication, during 7 consecutive days during the week immediately following the ABPM. Self-measured BP values were transmitted wireless by mobile phone to a website (VitalCare telemonitoring platform of Vitalsys, Antwerp, Belgium). All six measurements during the first day as well as every first measurement in the following sets of three measurements were excluded and mean tele-HBPM was calculated on the second and third measurement of each set from day 2 to day 7 .

\section{Definitions and hypertension control}

Hypertension was defined as a mean office systolic $\mathrm{BP}$ (SBP) of at least $140 \mathrm{~mm} \mathrm{Hg}$ and/or a mean office diastolic BP (DBP) of at least $90 \mathrm{~mm} \mathrm{Hg}$, or current treatment for hypertension. Blood pressure control for office BP was defined as a BP threshold $<140 /<90 \mathrm{~mm} \mathrm{Hg}$, for self-measured home BP $<$ $135 /<85 \mathrm{~mm} \mathrm{Hg}$, for ABPM $<135 /<85 \mathrm{~mm} \mathrm{Hg}$ during daytime, $<120 /<70 \mathrm{~mm} \mathrm{Hg}$ during sleep, and $<130 /<80 \mathrm{~mm} \mathrm{Hg}$ for $24 \mathrm{~h} \mathrm{ABP}$.

White coat effect (WCE) is defined as the condition in which BP is repeatedly elevated in the office and normal on out-of-office measurements; whereas masked hypertension is defined as normal office BP and elevated out-of-office measurements.

\section{Questionnaires}

General wellbeing and psychological and emotional status of the subjects were analysed to evaluate if they would influence BP reproducibility, medication adherence and most of all satisfaction of the subjects with the different measurement techniques.

\section{Statistical analysis}

Data were analysed with Statview, version 5.0.1 (SAS Institute Inc.) Statistics and Data Analysis Software and MedCalc for Windows, version 13.2.0.0 (MedCalc Software, Ostend, Belgium) [27]. Demographic and clinical disease characteristics were summarized. Blood pressure values and control rates were summarized and compared, as well as global wellbeing, anxiety and depression, medication adherence and satisfaction concerning the type of BP measurement. For comparisons, Student's $t$-test for continuous variables and chi-square-tests for categorical variables and proportions were used.

The difference between the two different out-ofoffice techniques was first explored by using a paired $t$-test and by calculating correlation coefficients, and secondly by the Bland-Altman-Method for multiple measurements $[28,29]$. 
The study was conducted according to the Declaration of Helsinki ethical principles for medical research involving human subjects. The study was approved by the Ethics committee of the Universitair Ziekenhuis Brussel (BUN 143201318660 - 30 $0^{\text {th }}$ Oct 2013) and written patient informed consent was obtained.

\section{Results}

\section{Study sample}

Baseline characteristics of the study population are given in Table 2. The study group included 16 NT volunteers, 18 patients with $\mathrm{HT}$ without $\mathrm{CKD}$ and 23 patients with $\mathrm{HT}$ and $\mathrm{CKD}$. Out of the 60 initially included patients, 3 patients withdrew before starting the study, 3 patients only participated once and withdrew after the $2^{\text {nd }}$ visit. Therefore, the data of these three patients, even as the data of one patient whose therapy was accidentally modified between visit 2 and visit 3 , were excluded to compute reproducibility.

\section{Blood pressure assessed by office BPM, 24h-ABPM and tele-HBPM}

Average BP values for each measuring method at all visits are given in Table 3 and Supplementary Table S1. Tele-HBP and 24h-ABPM showed very good reproducibility as no significant differences were observed. On the other hand, mean office BP was significantly higher on the first two visits $(133 \pm 23 \mathrm{~mm} \mathrm{Hg})$ than on the last two visits $(130 \pm 17 \mathrm{~mm} \mathrm{Hg}, \mathrm{p}<0.05)$. Low reproducibility of systolic OBP was mainly due to a considerably higher variability in patients with HT and CKD stage 5D ( $\mathrm{p}=0.035)$.

Mean tele-HBP showed no significant difference with daytime-ABP in the overall study population, but tele-systolic-HBP was significantly lower than systolic OBP on both occasions.

The correlation coefficients between the two outof-office techniques were 0.748 and 0.702 for SBP and 0.705 and 0.752 for DBP on respectively the first and third visit $(p<0.0001)$.

Bland-Altman-Plots for multiple measurements for SBP as well as for DBP showed good agreement between the two different out-of-office techniques, i.e. daytime-ABPM and tele-HBPM. Tele-systolicHBP was only $1.3 \mathrm{~mm} \mathrm{Hg}$ lower than daytimesystolic-ABP. Tele-diastolic-HBP was $0.3 \mathrm{~mm} \mathrm{Hg}$ higher than daytime-diastolic-ABP (Fig. 2).

\section{$\mathrm{BP}$ control assessed by office BPM, 24h-ABPM and tele-HBPM}

In the patients with HT, BP control rates ranged between $50.0 \%$ and $69.4 \%$ according to the tech-

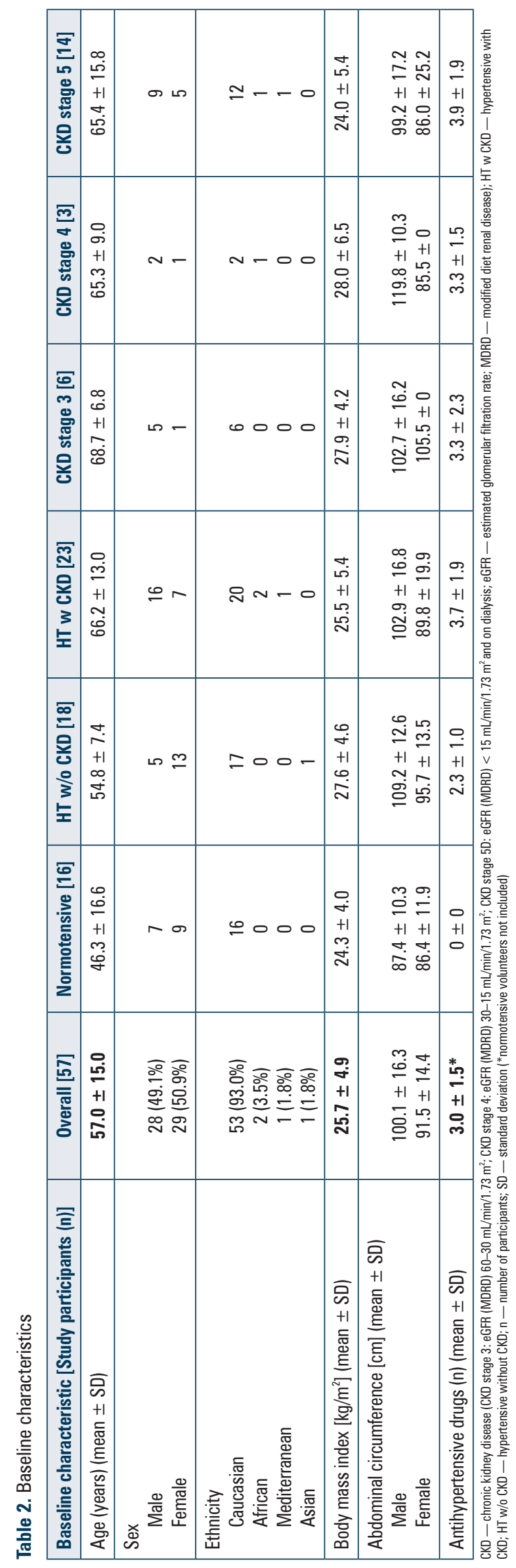


Table 3. Overview of office blood pressure (BP), ambulatory BP and home BP

\begin{tabular}{|c|c|c|c|c|}
\hline \multirow{2}{*}{ Blood pressure } & \multicolumn{2}{|c|}{ Visit $1+2$} & \multicolumn{2}{|c|}{ Visit $3+4$} \\
\hline & SBP $($ mean $\pm \mathrm{SD})$ & $\mathrm{DBP}($ mean $\pm \mathrm{SD})$ & SBP $($ mean $\pm \mathrm{SD})$ & $\mathrm{DBP}($ mean $\pm \mathrm{SD})$ \\
\hline Office blood pressure [mm Hg] & $\mathrm{n}=57$ & $\mathrm{n}=57$ & $\mathrm{n}=52$ & $\mathrm{n}=52$ \\
\hline All patients & $133.4 \pm 22.6^{\mathrm{b}, \mathrm{e}}$ & $76.5 \pm 12.2$ & $129.8 \pm 16.7^{* f}$ & $74.4 \pm 11.1$ \\
\hline $\begin{array}{l}\text { Normotensive } \\
\text { Hypertensive without CKD } \\
\text { Hypertensive with CKD } \\
\text { CKD stage } 3 \\
\text { CKD stage } 4 \\
\text { CKD stage } 5\end{array}$ & $\begin{array}{c}126.3 \pm 16.5 \\
124.6 \pm 18.8^{\mathrm{f}} \\
145.8 \pm 24.1^{\mathrm{a}, \mathrm{f}} \\
133.8 \pm 12.3^{\mathrm{f}} \\
143.4 \pm 15.2 \\
151.5 \pm 28.1^{\mathrm{b}}\end{array}$ & $\begin{array}{c}71.5 \pm 6.9 \\
77.6 \pm 15.5 \\
79.5 \pm 11.3 \\
79.3 \pm 8.3 \\
77.1 \pm 6.8 \\
80.1 \pm 13.4^{f}\end{array}$ & $\begin{array}{c}126.1 \pm 18.8 \\
124.0 \pm 14.6^{f} \\
136.4 \pm 15.2^{*} \\
128.7 \pm 16.1 \\
146.3 \pm 14.6 \\
137.6 \pm 14.4^{*}\end{array}$ & $\begin{array}{c}71.1 \pm 9.3 \\
77.1 \pm 11.7 \\
74.3 \pm 11.4^{*} \\
78.3 \pm 10.8 \\
80.5 \pm 12.7 \\
71.0 \pm 11.1^{* f}\end{array}$ \\
\hline Daytime-ABP [mm Hg] & $\mathrm{n}=57$ & $\mathrm{n}=57$ & $\mathrm{n}=54$ & $\mathrm{n}=54$ \\
\hline All patients & $129.1 \pm 17.4^{d}$ & $77.7 \pm 10.9$ & $126.7 \pm 14.0$ & $75.4 \pm 8.6^{*}$ \\
\hline $\begin{array}{l}\text { Normotensive } \\
\text { Hypertensive without CKD } \\
\text { Hypertensive with CKD } \\
\text { CKD stage } 3 \\
\text { CKD stage } 4 \\
\text { CKD stage } 5\end{array}$ & $\begin{array}{c}123.7 \pm 8.8 \\
124.4 \pm 17.2^{\mathrm{f}} \\
137.1 \pm 19.4^{\mathrm{c}} \\
124.8 \pm 8.8 \\
141.0 \pm 6.9 \\
141.6 \pm 22.5^{\mathrm{d}}\end{array}$ & $\begin{array}{c}74.0 \pm 9.2 \\
79.4 \pm 12.0^{f} \\
79.0 \pm 11.0 \\
76.0 \pm 6.5 \\
81.0 \pm 12.2 \\
79.9 \pm 12.7^{\dagger}\end{array}$ & $\begin{array}{c}126.6 \pm 13.6 \\
121.8 \pm 10.1 \\
131.5 \pm 15.2^{*} \\
127.7 \pm 12.9 \\
140.7 \pm 5.5 \\
131.2 \pm 17.4^{*}\end{array}$ & $\begin{array}{r}73.4 \pm 7.0 \\
77.5 \pm 8.4 \\
75.3 \pm 9.6 \\
76.5 \pm 4.8 \\
79.3 \pm 8.7 \\
73.8 \pm 11.5^{*} \\
\end{array}$ \\
\hline Tele-HBP [mm Hg] & $\mathrm{n}=57$ & $\mathrm{n}=57$ & $\mathrm{n}=52$ & $\mathrm{n}=52$ \\
\hline All patients & $127.7 \pm 19.3^{c}$ & $77.3 \pm 11.1$ & $125.7 \pm 13.8^{d}$ & $75.2 \pm 8.5$ \\
\hline $\begin{array}{l}\text { Normotensive } \\
\text { Hypertensive without CKD } \\
\text { Hypertensive with CKD } \\
\text { CKD stage } 3 \\
\text { CKD stage } 4 \\
\text { CKD stage } 5\end{array}$ & $\begin{array}{c}124.9 \pm 14.6 \\
118.4 \pm 13.9^{\mathrm{b}, \mathrm{d}} \\
137.9 \pm 21.2^{\mathrm{d}} \\
122.0 \pm 12.0^{\mathrm{d}} \\
133.2 \pm 6.1 \\
146.7 \pm 22.6\end{array}$ & $\begin{array}{c}73.7 \pm 4.9 \\
76.1 \pm 11.6^{\mathrm{b}} \\
80.9 \pm 12.9 \\
73.5 \pm 8.7 \\
75.2 \pm 8.3 \\
85.3 \pm 13.7^{\mathrm{b}, \mathrm{d}}\end{array}$ & $\begin{array}{c}124.1 \pm 12.6 \\
118.8 \pm 12.7^{d} \\
132.9 \pm 12.2 \\
124.0 \pm 8.8 \\
136.3 \pm 7.6 \\
136.4 \pm 12.9\end{array}$ & $\begin{array}{c}72.5 \pm 6.8 \\
76.5 \pm 9.6 \\
76.4 \pm 8.5 \\
75.8 \pm 4.8 \\
78.2 \pm 11.7 \\
76.2 \pm 9.8^{* d}\end{array}$ \\
\hline
\end{tabular}

ABP — ambulatory blood pressure; CKD — chronic kidney disease (CKD stage 3: eGFR (MDRD) 60-30 mL/min/1.73 m²; CKD stage 4: eGFR (MDRD) 30-15 mL/min/1.73 m²; CKD stage 5D: eGFR (MDRD) $\left.<15 \mathrm{~mL} / \mathrm{min} / 1.73 \mathrm{~m}^{2}\right) ; \mathrm{DBP}$ - diastolic blood pressure; eGFR — estimated glomerular filtration rate; MDRD - modified diet renal disease; $\mathrm{n}$ - number of patients; $\mathrm{SBP}$ - systolic blood pressure; $\mathrm{SD}$ - standard deviation; tele-HBP - telemedicine-guided home blood pressure; * ${ }^{*}<0.05$ compared to visit $1+2 ;$ a $<<0.005 ; \mathrm{bp}<0.05$ compared to daytime-ABP; $\mathrm{cp}<0.005 ; \mathrm{dp}<0.05$ compared to office-BP; ep $<0.005 ; \mathrm{fp}<0.05$ compared to tele-HBP
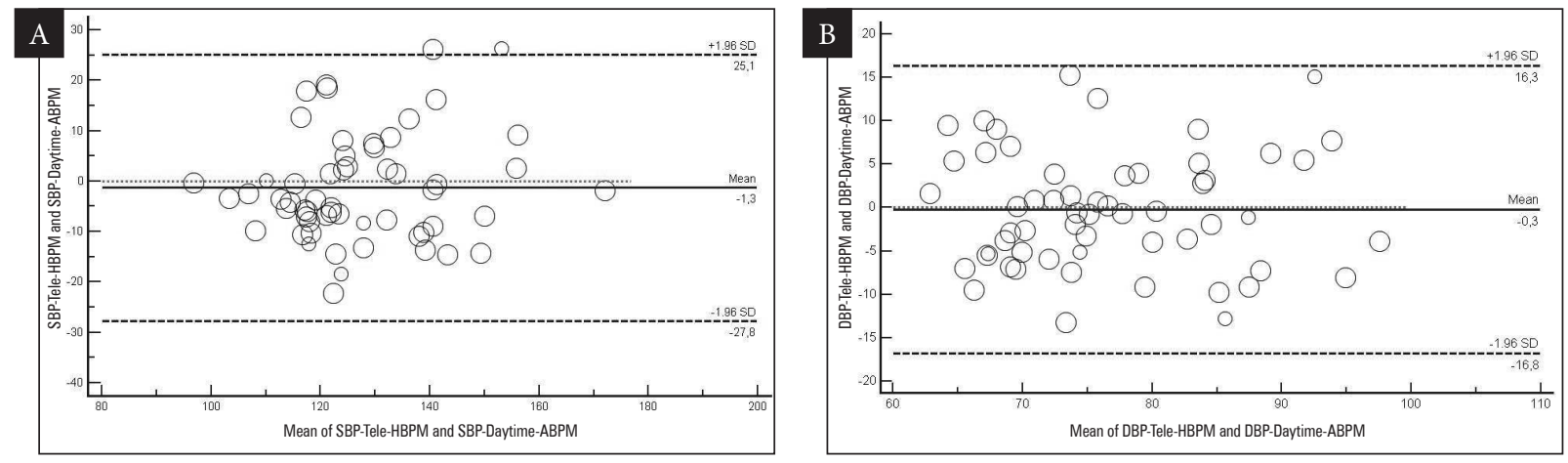

Figure 2: Bland-Altman-Plot for multiple measurements by tele-HBPM and daytime-ABPM; A — systolic blood pressure (SBP); B - diastolic blood pressure (DBP)

nique used (Tab. 4 and Supplementary Tab. S2). During the second measurement week, significant more patients had better BP control. Blood pressure control assessed by tele-HBPM compared with daytime-ABPM showed significant difference on both occasions ( $p=0.0087$ and 0.0235 on respectively the first and second measurement), although in the opposite direction.
The prevalence of WCE and masked hypertension in HT patients varied respectively between $25.9-32.1 \%$ and $21.4-25.9 \%$ for tele-HBPM, and $21.4-31.0 \%$ and $27.6-34.6 \%$ for daytime-ABPM.

Night-time hypertension was observed in $54.8 \%$ and $46.4 \%$ in patients with hypertension and in $0 \%$ and $7.1 \%$ in subjects not known with HT, respectively on the first and second ABPM. 
Table 4. The proportion of hypertensive patients with controlled blood pressure (BP) and uncontrolled BP according to office BP, $24 \mathrm{~h}$ ambulatory blood pressure (24h-ABPM) and telemedicine-guided home blood pressure (tele-HBPM)

\begin{tabular}{|l|c|c|c|c|}
\hline BP measurement & BP at goal (\%) & Uncontrolled SBP (\%) & Uncontrolled DBP (\%) & $\begin{array}{c}\text { Uncontrolled SBP } \\
\text { and DBP (\%) }\end{array}$ \\
\hline Mean office BP & & & & 7.9 \\
\hline Visit 1 and 2 & 50.0 & 39.4 & 2.6 & 8.1 \\
Visit 3 and 4 & $64.9^{*}$ & 27.0 & 0.0 & 18.9 \\
\hline Mean daytime-ABP & & & & 8.1 \\
\hline Daytime-ABPM 1 & 56.8 & 21.6 & 10.8 & 16.7 \\
Daytime-ABPM 2 & $56.8^{*}$ & 24.3 & & 5.6 \\
\hline Mean tele-HBP & & & 8.3 & 5.6 \\
\hline Tele-HBPM 1 & $55.6^{\Delta}$ & 19.4 & 19.4 & \\
Tele-HBPM 2 & $69.4^{* \Delta}$ & & & \\
\hline
\end{tabular}

$\mathrm{ABP}$ - ambulatory blood pressure; $\mathrm{BP}$ - blood pressure; $\mathrm{DBP}$ — diastolic blood pressure; $\mathrm{SBP}$ - systolic blood pressure; tele-HBP — telemedicine guided home blood pressure; ${ }^{*} \mathrm{p}<0.05$ between visit $1+2$ and visit $3+4 ;{ }^{\wedge} p<0.05$ between tele-HBPM and daytime ABPM, respectively on the first and second measurement

\section{Satisfaction with different types of out-of-office BP measurement}

Study subjects overall preferred tele-HBPM over $24 \mathrm{~h}-\mathrm{ABPM}(\mathrm{p}<0.0001$ in the overall population on both occasions). Tele-HBPM had a score that was analogous with "satisfied", whereas $24 \mathrm{~h}-\mathrm{ABPM}$ had a mean score analogous with "neither satisfied, neither unsatisfied". This difference in preference was present in all patient groups without significant difference in satisfaction amongst the different groups.

\section{Medication adherence and general wellbeing of the patient}

The MMAS- 8 value was $7.5 \pm 0.9$ and $7.6 \pm 0.8$ on respectively first and third visit, without significant differences between the different patient groups.

The overall study group scored in the normal range for HADS-anxiety and HADS-depression (Supplementary Figure S1) [25, 26]. Overall values for HADS-anxiety and HADS-depression were 3.8 \pm 2.4 and $3.6 \pm 2.7$, and $4.4 \pm 3.5$ and $4.4 \pm 4.2$, both on respectively the first and third visit. The HADS-anxiety and HADS-depression values of the normotensive subjects were significantly better than those of the hypertensive patients.

The visual analogue scale (VAS) showed an overall health status of $76.0 \%$ the first time and $73.9 \%$ the second time, with again a significant difference between NT subjects and hypertensive patients. Normotensive subjects had a better health status as they scored better on every aspect of the EQ-5D descriptive system on both occasions. Worst values were found in hypertensive patients with stage $5 \mathrm{CKD}$, on haemodialysis, on both visits.

\section{Discussion}

We observe a very good agreement between both out-of-office methods in NT volunteers, as well as in HT patients with or without CKD, with only a small systematic error between both measurements. Both out-of-office techniques show similar absolute BP values in a heterogeneous cohort of subjects with and without hypertension. We can therefore conclude that tele-HBPM is equivalent to ABPM for evaluating daytime SBP and DBP. Our results are in line with the data found by Mansoor et al. who also used tele-HBPM [21] and with the results of others, using HBPM with automatically stored readings (storageHBPM) and ABPM [13-17, 20-23]. However, very few studies have used tele-HBPM.

Previous studies comparing conventional-HBPM and storage-HBPM revealed precise values in only $68-76 \%$ of the cases in the manual logbook entries [7]. Tele-HBPM has the same advantages of manual registration of BP values, but improves data quality reporting, decreases the chance of false reporting by the patient, and makes interpretation by physicians easier. Although there is no evidence so far for better results on long-term morbidity or mortality, tele-HBPM significantly increases compliance and BP control, and with a possible additional effect beyond conventional-HBPM [7, 30-38]. However, all meta-analysis concluded that the heterogeneity between studies in terms of intervention, technology and study design makes it difficult to make firm conclusions $[32,38]$. The telemonitoring-system has some disadvantages too, as it may be a complex procedure for some patients, and it is more expensive compared to office BP measurements [31]. In 
contrast to 24h-ABPM, tele-HBPM doesn't provide any information on night-time BP. In our cohort, the BP load, expressed as percentage of systolic/ diastolic readings $\geq 120 / \geq 70 \mathrm{~mm} \mathrm{Hg}$ and $\geq 135 / \geq$ $85 \mathrm{~mm} \mathrm{Hg}$ during night and day, respectively, is significantly higher during night-time compared to daytime (49\% vs. 43\%) [39]. The latter emphasizes the importance of $24 \mathrm{~h}-\mathrm{ABPM}$ in assessing hypertensive patients, as night-time-ABP has been suggested to be a more sensitive predictor of patients with higher CV-risk [1].

$\mathrm{BP}$ values are very similar between the two series of measurements, irrespective of the used BP measurement technique, except in patients with CKD stage 5 . This indicates that measuring and evaluating BP in patients on haemodialysis remains difficult, even with out-of-office devices, which corresponds with earlier publications, but without telemedicine [2, 40-42]. It also implies that measurements performed according to a standardised manner as recommended by the guidelines, increases reproducibility and decreases the WCE [43-46].

In the hypertensive patients, intensive BP monitoring significantly increases BP control, irrespectively of the technique used. These findings are in line with previous studies showing better $\mathrm{BP}$ control when patients have an intensive follow-up. [47-50]. Possible reasons for better BP control at the second intervention period could be: (1) Better medication adherence, although the MMAS-8-questionnaire reveals no significant difference between the first and second series of measurements. However this is a self-reported questionnaire and may be biased. Moreover since adherence is already very high the first time, obtaining significant changes in a small number of subjects is very hard; (2) Decrease in anxiousness and improvement in general wellbeing due to close monitoring. However, both questionnaires on general wellbeing do not reveal a decrease in anxiousness or depression; or (3) Habituation to the method which results in less stress on the moment of measurement and a better sleeping pattern during 24h-ABPM.

Overall study subjects, regardless of their age, BP status, or kidney function are more satisfied with teleHBPM than 24h-ABPM. Lower satisfaction rates for $24 \mathrm{~h}-\mathrm{ABPM}$ may be explained by the frequency of preprogramed and additional BP measurements, taken when the arm is not held still or when there is a nod in the cable, shortening the measurement interval. The $24 \mathrm{~h}-\mathrm{ABPM}$ may also interfere with daily activities and disturb sleeping pattern. The lat- ter is considered by several studies to be an important reason for dissatisfaction [51-53]. Furthermore pain, skin irritation and bruising are accounted responsible for lower satisfaction with ABPM [53].

In our overall study population the preference for further follow-up is tele-HBPM, regardless of their BP status or kidney function; but younger people (20's to 50's) are less unanimous. Although all younger people are also more satisfied with teleHBPM than 24h-ABPM, an equal part $(50 \%)$ of them prefer tele-HBPM to $24 \mathrm{~h}-\mathrm{ABPM}$ for further follow-up compared to $70-80 \%$ of the elderly people. The fact that younger people have less tendency to choose tele-HBPM for further follow-up may be explained by the assumption that on the one hand younger people are part of the working class and/or have young children to look after and consequently have less time. On the other hand elderly people are retired and do not mind spending some extra time on measuring $\mathrm{BP}$ thrice in the morning and in the evening. We think that these arguments surpass the greater satisfaction with tele-HBPM in their choice for further follow-up.

Our study has several strengths. This is a prospective study with three different BP measurement techniques in normotensive volunteers and in hypertensive patients with and without $\mathrm{CKD}$. The design is made in a way that we obtained several office $\mathrm{BP}$ values, measured according to the recommended guidelines and thereby increasing reproducibility and reliability. The same accounts for $24 \mathrm{~h}-\mathrm{ABPM}$ and tele-HBPM.

On the other hand a limitation of this pilot study is the limited number of patients. Both tele-HBPM and $24 \mathrm{~h}-\mathrm{ABPM}$ have some constraints. We encountered several potential technical difficulties with teleHBPM, i.e. mistakes in the pre-set date of the device, a not fully charged or out of service mobile phone and an unannounced upgrade of the system by the responsible company whereby data were not automatically transmitted. Tele-HBPM also asks a great participation of the patient. This may have positive effects on the awareness of her/his hypertensive status, but it makes physicians also more dependent on the patients' collaboration. Some patients had few measurements because they did not take the device with them when not returning home, they forgot to take their BP, or it was not compatible with their social life. It also requires very accurate explanation how to measure BP at home and transfer the data with a telemedicine-guided BPM device, which is time-consuming. 


\section{Conclusion}

In summary, we can conclude that the effectiveness of both out-of-office BP measuring techniques (telemedicine-guided HBP and daytime-ABP) in assessing $\mathrm{BP}$ and $\mathrm{BP}$ control rates is very comparable in normotensive subjects as well as in HT patients without and with CKD.

Out-of-office BPM techniques are the ones best used for further follow-up as they have better reproducibility than office BP. Most patients are more satisfied with tele-HBPM than with ABPM and prefer to have a follow-up by tele-HBPM rather than by 24h-ABPM.

Tele-HBPM is a promising diagnostic and therapeutic tool, but long-term studies are needed to determine the cost-effectiveness.

\section{Acknowledgements}

Our thanks go to all study volunteers and patients of the department of Nephrology and Hypertension of the UZ Brussel. Special thanks go to Mrs. N. Marmitte who helped us with all administrative requests and to Mrs. N. Fenners for the secretarial help.

\section{Authorship}

X.G. - execution and interpretation of the data being published, wrote the paper, approved the final version of the manuscript and agrees to the conditions of publication. T.R. - execution and interpretation of the data being published, approved the final version of the manuscript and agrees to the conditions of publication. P.V.N - conception and design of the study, wrote the paper and supervised the study progress, approved the final version of the manuscript and agrees to the conditions of publication.

\section{Conflicts of interest}

None.

\section{References}

1. Williams B, Mancia G, Spiering W, et al. 2018 ESC/ESH Guidelines for the management of arterial hypertension. J Hypertens. 2018; 36(10): 1953-2041, doi: 10.1097/hjh.0000000000001940, indexed in Pubmed: 30234752.

2. Cohen D, Huan Y, Townsend R. Home Blood Pressure Monitoring in CKD. Am J Kidney Dis. 2014; 63(5): 835-842, doi: 10.1053/j. ajkd.2013.12.015, indexed in Pubmed: 24529535.

3. Stergiou G, Kollias A, Zeniodi M, et al. Home Blood Pressure Monitoring: Primary Role in Hypertension Management. Curr Hypertens Rep. 2014; 16(8), doi: 10.1007/s11906-014-0462-8, indexed in Pubmed: 2492499.

4. Bliziotis I, Destounis A, Stergiou G. Home versus ambulatory and office blood pressure in predicting target organ damage in hypertension. J Hypertens. 2012; 30(7): 1289-1299, doi: 10.1097/ hjh.0b013e3283531eaf, indexed in Pubmed: 22499289.
5. Shimbo D, Abdalla M, Falzon L, et al. Studies comparing ambulatory blood pressure and home blood pressure on cardiovascular disease and mortality outcomes: a systematic review. J Am Soc Hypertens. 2016; 10(3): 224-234.e17, doi: 10.1016/j.jash.2015.12.013, indexed in Pubmed: 26822864

6. Myers M, Stergiou G. Reporting bias: Achilles' heel of home blood pressure monitoring. J Am Soc Hypertens. 2014; 8(5): 350-357, doi: 10.1016/j.jash.2014.02.001, indexed in Pubmed: 24690268.

7. Parati G, Omboni S. Role of home blood pressure telemonitoring in hypertension management. Blood Press Monit. 2010; 15(6): 285-295, doi: $10.1097 / \mathrm{mbp} .0 \mathrm{~b} 013 \mathrm{e} 328340 \mathrm{c} 5 \mathrm{e} 4$, indexed in Pubmed: 21084882.

8. Hodgkinson J, Mant J, Martin U, et al. Relative effectiveness of clinic and home blood pressure monitoring compared with ambulatory blood pressure monitoring in diagnosis of hypertension: systematic review. BMJ. 2011; 342: d3621-d3621, doi: 10.1136/bmj.d3621, indexed in Pubmed: 21705406.

9. Mart??nez M, Sancho T, Garc??a P, et al. Home blood pressure in poorly controlled hypertension: relationship with ambulatory blood pressure and organ damage. Blood Press Monit. 2006; 11(4): 207-213, doi: 10.1097/01.mbp.0000209073.30708.e1, indexed in Pubmed: 16810031.

10. Bayó J, Cos F, Roca C, et al. Home blood pressure self-monitoring: diagnostic performance in white-coat hypertension. Blood Press Monit. 2006; 11(2): 47-52, doi: 10.1097/01.mbp.0000200479.19046.94, indexed in Pubmed: 16534404.

11. Mancia G, Zanchetti A, Agebiti-Rosei E, et al. Ambulatory Blood Pressure Is Superior to Clinic Blood Pressure in Predicting TreatmentInduced Regression of Left Ventricular Hypertrophy. Circulation. 1997; 95(6): 1464-1470, doi: 10.1161/01.cir.95.6.1464, indexed in Pubmed: 9118514.

12. Myers M, Valdivieso M, Chessman M, et al. Can sphygmomanometers designed for self-measurement of blood pressure in the home be used in office practice? Blood Press Monit. 2010; 15(6): 300-304, doi: $10.1097 / \mathrm{mbp} .0 \mathrm{~b} 013 \mathrm{e} 328340 \mathrm{~d} 128$, indexed in Pubmed: 20975533.

13. Hond E, Celis H, Fagard R, et al. Self-measured versus ambulatory blood pressure in the diagnosis of hypertension. J Hypertens. 2003; 21(4): 717-722, doi: 10.1097/00004872-200304000-00014, indexed in Pubmed: 12658017.

14. Hara A, Tanaka K, Ohkubo T, et al. Ambulatory Versus Home Versus Clinic Blood Pressure. Hypertension. 2012; 59(1): 22-28, doi: 10.1161/hypertensionaha.111.174938, indexed in Pubmed: 22083163.

15. Stergiou G, Skeva I, Baibas N, et al. Diagnosis of hypertension using home or ambulatory blood pressure monitoring. J Hypertens. 2000; 18(12): 1745-1751, doi: 10.1097/00004872-200018120-00007, indexed in Pubmed: 11132597.

16. Lamarre-Cliché M, Cheong N, Larochelle P. Comparative Assessment of Four Blood Pressure Measurement Methods in Hypertensives. Can J Cardiol. 2011; 27(4): 455-460, doi: 10.1016/j.cjca.2011.05.001, indexed in Pubmed: 2180197.

17. Anstey D, Muntner P, Bello N, et al. Diagnosing Masked Hypertension Using Ambulatory Blood Pressure Monitoring, Home Blood Pressure Monitoring, or Both? Hypertension. 2018; 72(5): 1200-1207, doi: 10.1161/hypertensionaha.118.11319, indexed in Pubmed: 30354812.

18. Robberechts T, Allamani M, Van der Niepen P. Hyponatremic versus isonatremic dialysate in patients with intradialytic hypertension. A randomised controlled trial. Poster session presented at: 25 th European Meeting on Hypertension and Cardiovasculair Protection, 25th Scientific Meeting of the European Society of Hypertension 12-15 June 2015, Milan, Italy.

19. Gaborieau V, Delarche N, Gosse P. Ambulatory blood pressure monitoring versus self-measurement of blood pressure at home: correlation with target organ damage. J Hypertens. 2008; 26(10): 1919-1927, doi: 10.1097/hjh.0b013e32830c4368, indexed in Pubmed: 18806615.

20. Stergiou G, Argyrak K, Moyssakis I, et al. Home Blood Pressure Is as Reliable as Ambulatory Blood Pressure in Predicting TargetOrgan Damage in Hypertension. Am J Hypertens. 2007; 20(6): 
616-621, doi: 10.1016/j.amjhyper.2006.12.013, indexed in Pubmed: 17531917.

21. Mansoor G, White W. Self-measured home blood pressure in predicting ambulatory hypertension. Am J Hypertens. 2004; 17(11): 1017-1022, doi: 10.1016/j.amjhyper.2004.06.015, indexed in Pubmed: 15533727

22. Shimbo D, Pickering T, Spruill T, et al. Relative Utility of Home, Ambulatory, and Office Blood Pressures in the Prediction of End-Organ Damage. Am J Hypertens. 2007; 20(5): 476-482, doi: 10.1016/j. amjhyper.2006.12.011, indexed in Pubmed: 17485006.

23. Jula A, Puukka P, Karanko H. Multiple Clinic and Home Blood Pressure Measurements Versus Ambulatory Blood Pressure Monitoring. Hypertension. 1999; 34(2): 261-266, doi: 10.1161/01. hyp.34.2.261

24. O'Shaughnessy M, Durcan M, Kinsella S, et al. Blood Pressure Measurement in Peritoneal Dialysis: Which Method is Best? Perit Dial Int. 2020; 33(5): 544-551, doi: 10.3747/pdi.2012.00027, indexed in Pubmed: 23547279.

25. Zigmond AS, Snaith RP. The Hospital Anxiety and Depression Scale. Acta Psychiatr Scand. 1983; 67(6): 361-370, doi: 10.1111/j.16000447.1983.tb09716.x, indexed in Pubmed: 6880820.

26. Bjelland I, Dahl A, Haug T, et al. The validity of the Hospital Anxiety and Depression Scale. J Psychosom Res. 2002; 52(2): 69-77, doi: 10.1016/s0022-3999(01)00296-3, indexed in Pubmed: 11832252.

27. Bland-Altman plot with multiple measurements per subject, MedCalc Software bvba, consulted on 12th of May 2014. http://www. medcalc.org/manual/blandaltmanmultiple.php.

28. Altman DG, Bland JM. Measurement in Medicine: The Analysis of Method Comparison Studies. Statistician. 1983; 32(3): 307, doi: $10.2307 / 2987937$.

29. Bland JM, Altman D. Statistical methods for assessing agreement between two methods of clinical measurement. Lancet. 1986; 327(8476): 307-310, doi: 10.1016/s0140-6736(86)90837-8, indexed in Pubmed: 2868172.

30. Stergiou G, Nasothimiou E. Does home telemonitoring improve hypertension management? Nat Rev Nephrol. 2011; 7(9): 493-495, doi: 10.1038/nrneph.2011.108, indexed in Pubmed: 21808275.

31. Madsen L, Christiansen T, Kirkegaard P, et al. Economic evaluation of home blood pressure telemonitoring: A randomized controlled trial. Blood Press. 2010; 20(2): 117-125, doi: 10.3109/08037051 .2010.532306, indexed in Pubmed: 21105759.

32. Agarwal R, Bills J, Hecht T, et al. Role of Home Blood Pressure Monitoring in Overcoming Therapeutic Inertia and Improving Hypertension Control. Hypertension. 2011; 57(1): 29-38, doi: 10.1161/ hypertensionaha.110.160911, indexed in Pubmed: 21115879.

33. Omboni S, Guarda A. Impact of Home Blood Pressure Telemonitoring and Blood Pressure Control: A Meta-Analysis of Randomized Controlled Studies. Am J Hypertens. 2011; 24(9): 989-998, doi: 10.1038/ajh.2011.100, indexed in Pubmed: 21654858.

34. Kerby T, Asche S, Maciosek M, et al. Adherence to Blood Pressure Telemonitoring in a Cluster-Randomized Clinical Trial. J Clin Hypertens (Greenwich). 2012; 14(10): 668-674, doi: 10.1111/j.17517176.2012.00685.x, indexed in Pubmed: 23031143.

35. Krakoff L. Management of Cardiovascular Risk Factors Is Leaving the Office: Potential Impact of Telemedicine. J Clin Hypertens (Greenwich). 2011; 13(11): 791-794, doi: 10.1111/j.17517176.2011.00534.x, indexed in Pubmed: 22051422.

36. McKinstry B, Hanley J, Wild S, et al. Telemonitoring based service redesign for the management of uncontrolled hypertension: multicentre randomised controlled trial. BMJ. 2013; 346: f3030, doi: 10.1136/bmj.f3030, indexed in Pubmed: 23709583.

37. Stoddart A, Hanley J, Wild S, et al. Telemonitoring-based service redesign for the management of uncontrolled hypertension (HITS): cost and cost-effectiveness analysis of a randomised controlled trial. BMJ Open. 2013; 3(5): e002681, doi: 10.1136/bmjopen-2013-002681, indexed in Pubmed: 23793650.

38. Omboni S. Connected Health in Hypertension Management. Front Cardiovasc Med. 2019; 6, doi: 10.3389/fcrm.2019.00076, indexed in Pubmed: 31263703.

39. Kikuya M, Hansen T, Thijs L, et al. Diagnostic thresholds for ambulatory blood pressure monitoring based on 10-year cardiovascular risk. Circulation. 2007; 15(16): 2145-2152, doi: 10.1161/CIRCULATIONAHA.106.662254, indexed in Pubmed: 17420350.

40. Palatini P. Ambulatory blood pressure and cardiovascular risk in chronic kidney disease. Curr Hypertens Rep. 2008; 10(2): 119-126, doi: 10.1007/s11906-008-0023-0, indexed in Pubmed: 18474178.

41. Andersen M, Khawandi W, Agarwal R. Home Blood Pressure Monitoring in CKD. Am J Kidney Dis. 2005; 45(6): 994-1001, doi: 10.1053/j.ajkd.2005.02.015, indexed in Pubmed: 15957127.

42. Minutolo R, Borrelli S, Chiodini P, et al. Effects of age on hypertensive status in patients with chronic kidney disease. J Hypertens. 2007; 25(11): 2325-2333, doi: 10.1097/hjh.0b013e3282ef549e, indexed in Pubmed: 17921829.

43. Myers MG, Godwin M, Dawes M, et al. Conventional versus automated measurement of blood pressure in primary care patients with systolic hypertension: randomised parallel design controlled trial. BMJ. 2011; 342: d286-d286, doi: 10.1136/bmj.d286, indexed in Pubmed: 21300709.

44. Myers M. Replacing manual sphygmomanometers with automated blood pressure measurement in routine clinical practice. Clin Exp Pharmacol Physiol. 2013; 41(1): 46-53, doi: 10.1111/14401681.12149, indexed in Pubmed: 23819734.

45. Myers M. Eliminating the Human Factor in Office Blood Pressure Measurement. J Clin Hypertens (Greenwich). 2014; 16(2): 83-86, doi: $10.1111 /$ jch.12252, indexed in Pubmed: 24387759.

46. Myers MG, Kaczorowski J, Dawes M, et al. Automated office blood pressure measurement in primary care. Can Fam Physician. 2014; 60: 127-132, indexed in Pubmed: 24522674.

47. McManus RJ, Mant J, Bray EP, et al. Telemonitoring and self-management in the control of hypertension (TASMINH2): a randomised controlled trial. Lancet. 2010; 376: 163-172, doi: 10.1016/S01406736(10)60964-6, indexed in Pubmed: 20619448.

48. Margolis K, Asche S, Bergdall A, et al. Effect of Home Blood Pressure Telemonitoring and Pharmacist Management on Blood Pressure Control. JAMA. 2013; 310(1): 46, doi: 10.1001/jama.2013.6549, indexed in Pubmed: 23821088.

49. Glynn L, Murphy A, Smith S, et al. Interventions used to improve control of blood pressure in patients with hypertension. Cochrane Database Syst Rev. 2010, doi: 10.1002/14651858.cd005182.pub4, indexed in Pubmed: 20238338.

50. Margolis K, Asche S, Dehmer S, et al. Long-term Outcomes of the Effects of Home Blood Pressure Telemonitoring and Pharmacist Management on Blood Pressure Among Adults With Uncontrolled Hypertension. JAMA Netw Open. 2018; 1(5): e181617, doi: 10.1001/ jamanetworkopen.2018.1617, indexed in Pubmed: 30646139.

51. Staessen J, Fagard R, Thijs L, et al. A Consensus View on the Technique of Ambulatory Blood Pressure Monitoring. Hypertension. 1995; 26(6): 912-918, doi: 10.1161/01.hyp.26.6.912, indexed in Pubmed: 7490148.

52. Elliot L, Iqbal P. Factors associated with probability of patient rejecting a repeat $24 \mathrm{~h}$ ambulatory blood pressure monitoring, despite recommendation by the physician. Blood Press Monit. 2003: 191-194, doi: 10.1097/00126097-200310000-00003, indexed in Pubmed: 14624168.

53. Viera A, Lingley K, Hinderliter A. Tolerability of the Oscar 2 ambulatory blood pressure monitor among research participants: a cross-sectional repeated measures study. BMC Med Res Methodol. 2011; 11(1), doi: 10.1186/1471-2288-11-59, indexed in Pubmed: 21524301. 